\title{
Comprehensive analytical and structural characteristics of methyl 3,3-dimethyl-2-(1-(pent-4-en-1-yl)-1H-indazole-3-carboxamido) butanoate (MDMB-4en-PINACA)
}

\author{
Michal P. Dybowski ${ }^{1}$ - Piotr Holowinski ${ }^{1} \cdot$ Rafal Typek$^{1} \cdot$ Andrzej L. Dawidowicz $^{1}$
}

Received: 3 January 2021 / Accepted: 20 March 2021 / Published online: 1 April 2021

(c) The Author(s) 2021

\begin{abstract}
Purpose The purpose of the study was to evaluate a complete analytical and structural characterization of methyl 3,3-dimethyl-2-(1-(pent-4-en-1-yl)-1H-indazole-3-carboxamido)butanoate (MDMB-4en-PINACA), a novel synthetic cannabinoid being the analogue of 5F-ADB.

Methods The compound was analyzed by gas chromatography-mass spectrometry (GC-MS), high-resolution liquid chromatography-mass spectrometry (LC-MS), X-ray diffraction and spectroscopic methods, such as nuclear magnetic resonance (NMR) and Fourier-transform infrared (FTIR) spectroscopies. To derive MDMB-4en-PINACA molecular geometry and to assign infrared absorption bands, quantum calculations with the employment of density functional theory were also used.

Results We present a wide range of chromatographic and spectroscopic data supported with theoretical calculations allowing to identify MDMB-4en-PINACA.

Conclusions To our knowledge, this is the first report presenting a comprehensive analytical and structural characterization of MDMB-4en-PINACA obtained by 1D and 2D NMR, GC-MS, LC-MS(/MS), attenuated total reflection-FTIR spectroscopy, powder X-ray diffraction and quantum chemical calculations. The presented results not only broaden the knowledge about this psychoactive substance but also are useful for forensic and clinical purposes.
\end{abstract}

Keyword MDMB-4en-PINACA · Comprehensive analytical characteristics · 1D and 2D NMR · Powder X-ray diffraction · Quantum chemical calculations

\section{Introduction}

Among the wide range of psychoactive substances used notoriously in recent years, synthetic cannabinoids deserve special attention [1]. When used for recreational purposes, they often bring about psychophysical states difficult to control and leading to numerous accidents, fatalities and severe social consequences [2-4]. One of the most prevalent subclasses of synthetic cannabinoids is the group of compounds with 3-carboxyamide indazole entity-i.e., with the structural motif probably coming from novel compounds with cannabinoids activity patented by Pfizer [5, 6]. Many of

Michal P. Dybowski

m_dybowski@interia.pl

1 Department of Chromatography, Institute of Chemical Sciences, Faculty of Chemistry, Maria Curie Sklodowska University in Lublin, 20-031 Lublin, Poland them, e.g., ADB-CHMINACA and AB-CHMINACA, were directly implemented -as illicit substances [7, 8], whereas some others were modified and increased the range of synthetic cannabinoids on the drug market. The most frequently employed structural alternation among several modifications was the replacement of indazole core $\mathrm{N}$-substituent with pentyl or 5-halogenated pentyl chain. Such modification is easily explained by well-known QSAR observations of analogous indole-based cannabimimetics indicating that $\mathrm{N}$-alkyl chains containing from 4 to 6 carbon atoms cause effective hydrophobic interaction of a synthetic cannabinoid with its binding sites of $\mathrm{CB}_{1}$ and $\mathrm{CB}_{2}$ receptors [9]. Besides halogen atoms, different terminal groups were also attached to the alkyl chains of synthetic cannabinoids, e.g., nitrile and vinyl groups [10].

The paper presents the full analytical and structural characterization of MDMB-4en-PINACA, methyl 3,3-dimethyl-2-(1-(pent-4-en-1-yl)-1 $H$-indazole-3-carboxamido)butanoate (Fig. 1), a novel synthetic cannabinoid 
Fig. 1 Chemical structure of methyl 3,3-dimethyl-2-(1(pent-4-en-1-yl)- $1 H$-indazole3-carboxamido)butanoate (MDMB-4en-PINACA)

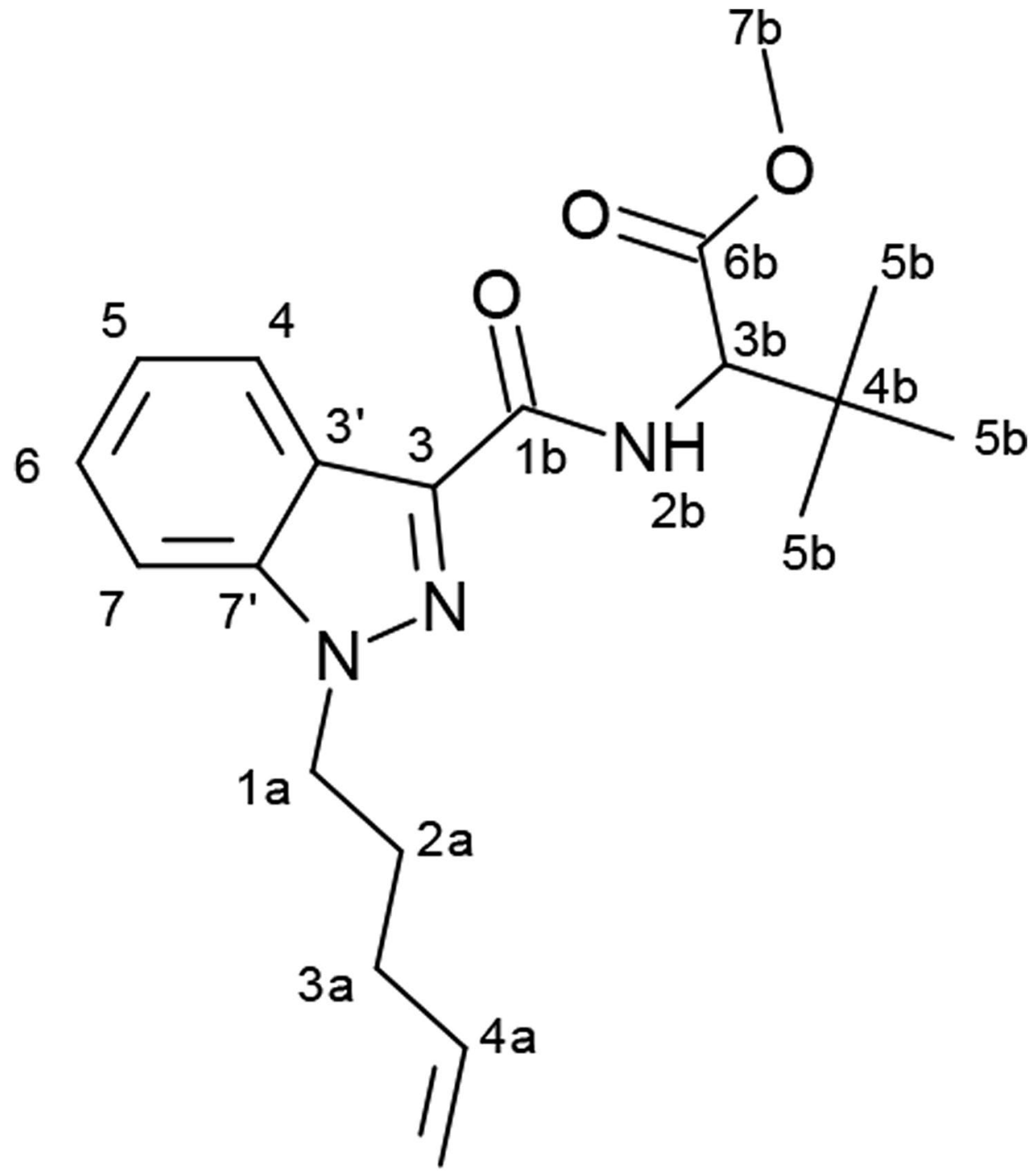

$5 a$ being the analogue of 5F-ADB, with pent-4-en-1-yl fragment in place of 5-fluoropentyl chain, found in the material seized by the Polish law authorities. Analytical features of MDMB-4en-PINACA were characterized by gas chromatography hyphenated with mass spectrometry (GC-MS), liquid chromatography (LC) with photodiode array (PDA) and mass spectrometry (MS) detection, attenuated total reflection Fourier-transform infrared (ATR-FTIR) spectroscopy, nuclear magnetic resonance (NMR) spectroscopy and powder X-ray diffraction. The density functional theory (DFT) quantum chemical methods were used to derive molecular geometry and to assign the infrared absorption bands. As far as we know, this is the first report showing a comprehensive analytical and structural characterization of MDMB-4en-Pinaca, which has already been examined, but only by some of the enlisted methods [11-16].

\section{Materials and methods}

\section{Materials}

Acetonitrile and methanol (all LC-MS grade) were supplied by the Polish Chemical Plant POCh (Gliwice, Poland); formic acid from Sigma-Aldrich (Seelze, Germany); deuterated chloroform from Armar AG (Döttingen, Switzerland); the Milli-Q system from Millipore (Millipore, Bedford, MA, USA) to be applied for water purification. MDMB-4en-PINACA sample was donated by the forensic laboratory of the Provincial Police Department in Lublin. Working solutions were stored in stable conditions at $-20{ }^{\circ} \mathrm{C}$. 


\section{GC-MS analysis}

The qualification of MDMB-4en-PINACA in the prepared solution was performed using GC-MS QP2010 (Shimadzu, Kyoto, Japan). GC-MS equipment details and measurement conditions are described in [17]. The retention index of the examined substance was calculated according to [18].

\section{LC analysis with photodiode array detection}

The UV-VIS spectrum for the tested compound was obtained using HPLC system equipped with a Thermo Scientific Dionex UltiMate DAD-3000 detector-1024 element diode array working with the frequency of collecting the spectrum equal $100 \mathrm{~Hz}$. The UV-VIS spectrum for the MDMB-4en-PINACA was recorded in the range 190-600 nm. The LC-PDA equipment details and measurements conditions are described in [17].

\section{LC-MS analysis}

The experiments were performed on an LC-MS(/MS) system consisting of a UHPLC chromatograph (UltiMate 3000; Dionex, Sunnyvale, CA, USA), a high-resolution (HR) linear ion trap quadrupole-Orbitrap mass spectrometer (LTQ-Orbitrap Velos; Thermo Fisher Scientific, San Jose, CA, USA) and an electrospray ionization (ESI) source. The LC-MS equipment details and measurements conditions are described in [17].

\section{High-resolution-MS/MS analysis with direct injection}

The solution of MDMB-4en-PINACA in methanol (5 $\mu \mathrm{g}$ / $\mathrm{mL}$ ) was directly introduced to the above linear trap quadrupole-Orbitrap mass spectrometer at the rate $50 \mu \mathrm{L} / \mathrm{min}$. The positive ionization mode with the ESI needle potential at $4.5 \mathrm{kV}$ was used. The function of secondary ion fragmentation $\left(\mathrm{MS}^{2}\right.$ ) was applied for the $m / z, 358$ ion. The collision energy used in the experiment was 10,15, 20, 25 and $30 \%$.

\section{ATR-FTIR}

The infrared (IR) spectrum of the examined compound was registered in the wavenumber range from 4000 to $400 \mathrm{~cm}^{-1}$ using a Nicolet ${ }^{\mathrm{TM}} \mathrm{iS} 50$ FTIR spectrometer (Thermo Fisher Scientific) with the ATR crystal.

\section{Powder X-ray diffraction}

The powder diffraction data of the seized material were obtained using an Empyrean diffractometer (PANalytical, Malvern, United Kingdom) equipped with $\mathrm{Cu}$ anode (voltage: - $40 \mathrm{kV}$; current: $25 \mathrm{~mA}$ ), registering signals in the $2 \theta$ range between $4.96^{\circ}$ and $90.03^{\circ}$ using a step size of $0.026^{\circ}$.

\section{NMR spectroscopy}

The examined compound (10 $\mathrm{mg}$ dissolved in $0.5 \mathrm{~mL}$ of $\mathrm{CDCl}_{3}$ ) was analyzed by NMR using an ASCEND 600 apparatus (Bruker, Bremen, Germany). The following NMR spectra were acquired:

- 1D: ${ }^{1} \mathrm{H},{ }^{13} \mathrm{C}$ and

- 2D: ${ }^{1} \mathrm{H}-{ }^{1} \mathrm{H}$ correlation spectroscopy (COSY), ${ }^{1} \mathrm{H}-{ }^{13} \mathrm{C}$ multiplicity-edited heteronuclear single quantum coherence (HSQC), ${ }^{1} \mathrm{H}-{ }^{13} \mathrm{C}$ heteronuclear multiple bond correlation (HMBC), ${ }^{1} \mathrm{H}-{ }^{1} \mathrm{H}$ nuclear Overhauser effect spectroscopy (NOESY)

The chemical shifts were referenced to the tetramethylsilane (TMS) signal.

\section{Quantum chemical calculations}

Conformer search for MDMB-4en-PINACA was performed using Pcmodel (Serena Software, Bloomington, IN, USA) utilizing MMFF94 force field [19]. The DFT method with B3LYP hybrid exchange correlation functional [20] and 6-31G basis set was employed for the initial geometry optimization of the obtained conformers. The geometries exhibiting the lowest energy were re-optimized on the B3LYP/6-311++G(d,p) level of theory. The final geometries were used for the calculation of vibrational frequencies. Described ab initio computations were performed using the NWChem package [21].

\section{Results}

\section{GC-MS}

The GC-MS chromatogram of methanolic extract of the seized material and the electron ionization (EI) MS spectrum of MDMB-4en-PINACA are presented in Figs. 2a and 3a, respectively. It can be observed that the obtained EI spectrum is in a good agreement with that from the SWGDRUG database. The estimated retention index equaled 2537. The structure of molecular ion and fragment ions corresponding to the most intense peaks are shown in Fig. 3b. The following ions can be recognized:

- Acylium-indazole-alkyl ion at $\mathrm{m} / z$ 241. The structure of this main ion is similar to the structure of the main ions 

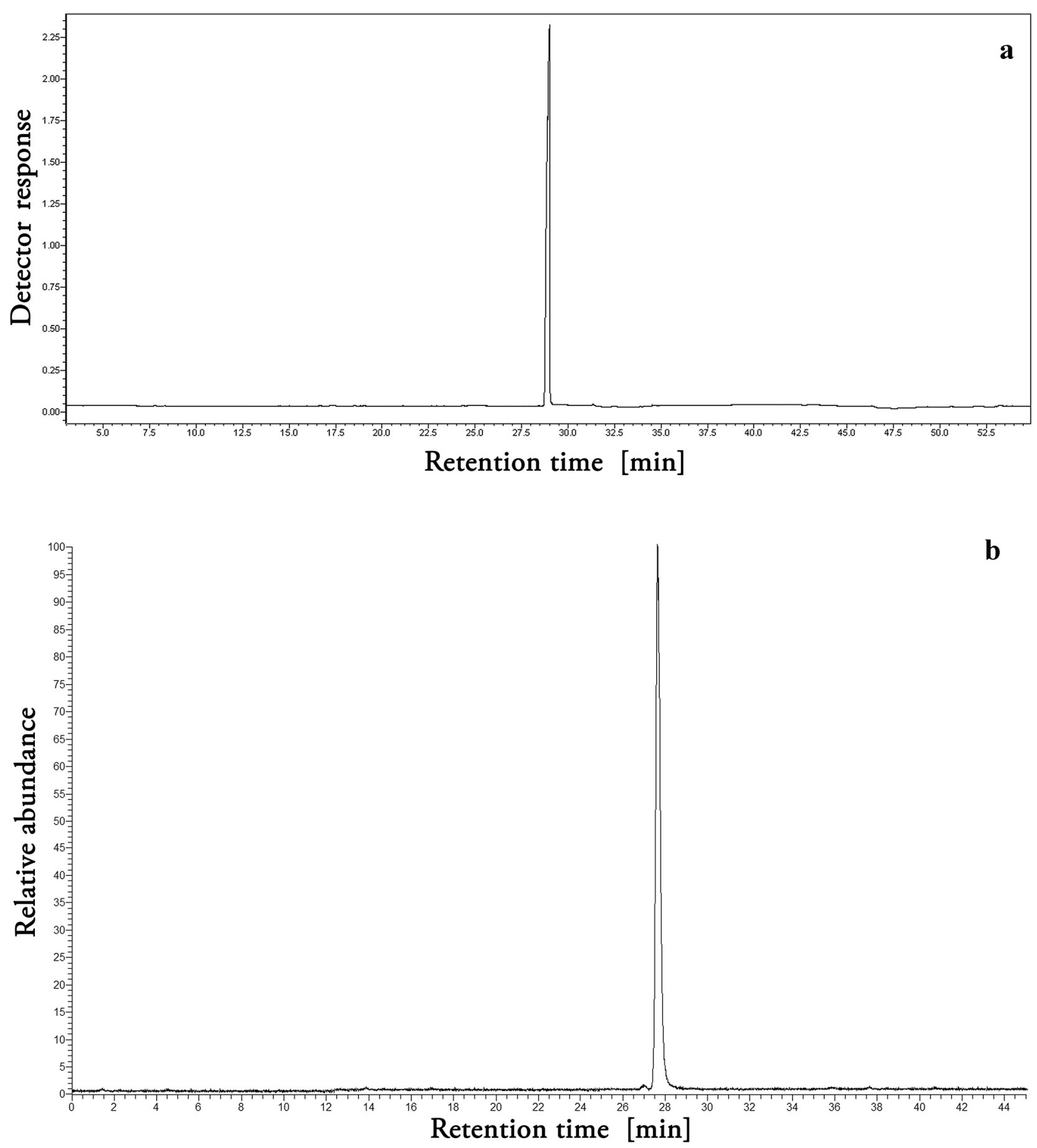

Fig. 2 a Gas chromatography-mass spectrometry (GC-MS) and b liquid chromatography-mass spectrometry (LC-MS) total ion chromatograms of MDMB-4en-PINACA

occurring in the EI-MS spectrum of other synthetic cannabinoids with carboxyindazole core;

- Acylium-indazole ion and methylidene-indazolium ion ( $\mathrm{m} / \mathrm{z} 145$ and 131, respectively), confirming the presence of indazole-carboxy moiety in the examined molecule, and
- $m / z, 301$ ion. This ion is the product of the McLafferty rearrangement of the molecular ion [22]. The visible $\mathrm{m} / \mathrm{z} 269$ fragment ion is formed by the loss of methanol molecule from the $m / z 301$ ion. The presence of these two ions is characteristic for the fragmentation 
a

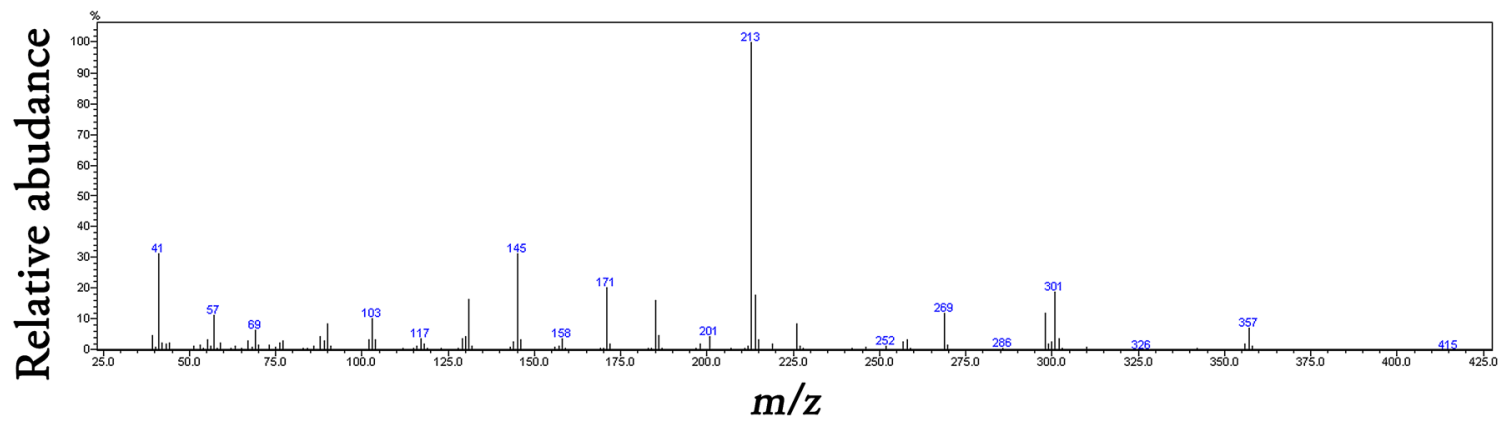

b<smiles></smiles>

$\mathrm{m} / \mathrm{z}=269$<smiles>[CH]=C</smiles><smiles>CC1CCCCC1</smiles>
$\mathrm{m} / \mathrm{z}=145$

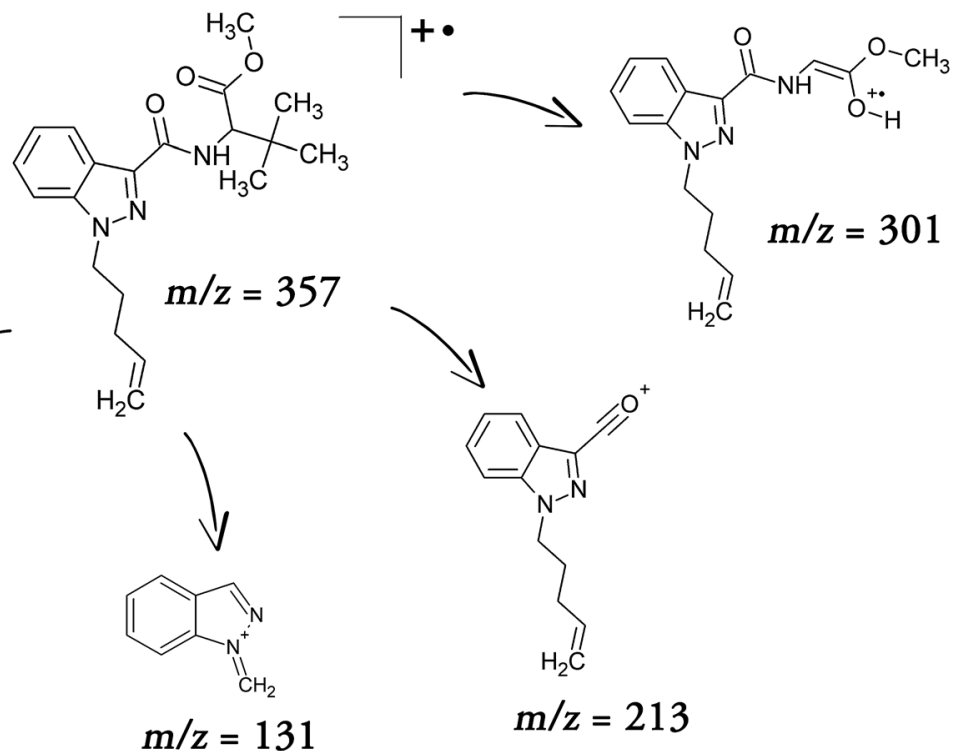

Fig. 3 a GC-electron ionization mass spectrum of MDMB-4en-PINACA and $\mathbf{b}$ its probable fragmentation pathways

pathways of synthetic cannabinoids containing tertleucinate residue attached to the carboxamide group.

\section{LC-MS, direct injection ESI-MS² and LC-PDA}

The exemplary LC-MS chromatogram of MDMB-4enPINACA methanolic solution is shown in Fig. 2b, whereas HR-MS data corresponding to this compound, for $30 \%$ collision energy (CE), are gathered in Table 1 . The obtained results indicate that the molecular weight of the MDMB-4enPINACA $[\mathrm{M}+\mathrm{H}]^{+}$ion and its elemental composition are as follows: $358.2132 \mathrm{Da}$ and $\mathrm{C}_{20} \mathrm{H}_{28} \mathrm{~N}_{3} \mathrm{O}_{3}$, respectively. The very low difference between the theoretical and the experimental mass $(\Delta \mathrm{ppm})$ for MDMB-4en-PINACA ions proved the correctness of the elemental analysis.

Figure 4 shows the influence of the applied fragmentation energy (CE) on the profile of ions forming during the
HR-MS/MS analysis with direct injection. The presented GC-MS and LC-MS data indicate a similarity between ESI and EI fragmentation patterns (see Figs. $3 b$ and 5).

As results from the LC-PDA analysis, two maxima (at $209 \mathrm{~nm}$ and at $301 \mathrm{~nm}$ ) are observed on the UV-VIS spectrum of MDMB-4en-PINACA (see supplementary material Fig. S1).

\section{NMR spectroscopy}

${ }^{1} \mathrm{H}$ and ${ }^{13} \mathrm{C}$ NMR spectra of the analyzed material dissolved in $\mathrm{CDCl}_{3}$ are shown in Figs. S2 and S3. The 2D spectra, required for the assignment of resonance signals, are presented in Figs. S4-S7. Table 2 summarizes the data from 1 and $2 \mathrm{D}$ spectra. The ${ }^{1} \mathrm{H}$ spectrum contains overlapping signals in the regions of 7.38-7.42, 5.03-5.08 and $2.04-2.13 \mathrm{ppm}$. Their assignment was mainly conducted with the use of HSQC and HMBC spectra. It is worth mentioning that, on the ${ }^{1} \mathrm{H}$ MDMB-4en-PINACA spectra, 


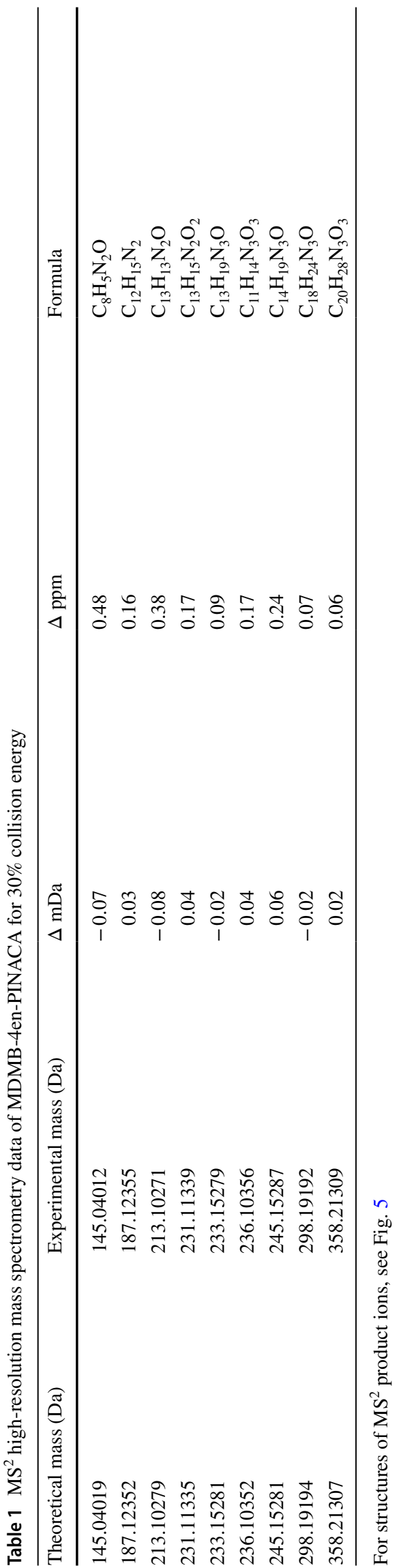

signals corresponding to dimethyl formamide $\left({ }^{1} \mathrm{H}\right.$ signals: $2.88 \mathrm{ppm}, 2.95 \mathrm{ppm}$ and $8.01 \mathrm{ppm}$ ) were also appearing, which indicated a probability of its usage as a solvent or a catalyst during the drug synthesis.

\section{Powder X-ray diffraction}

Powder X-ray diffraction was employed for the structural characterization of MDMB-4en-PINACA (see Fig. S8). All of the major peaks were observed in the range of $2 \theta$ below $35^{\circ}$, with the most intensive ones at the positions of $6.4,16.4$ and $19.1^{\circ}$. The calculated parameters of the crystal structure are as follows:

- Crystal system-monoclinic;

- Space group-P21; $a[\AA]=8.719(2) ; b[\AA]=8.552(3)$; $c[\AA]=14.284(3) ; \beta\left[^{\circ}\right]=103.62(2) ; V[\AA 3]=1035.1(5)$; $Z=2$

- Density: $1.147 \mathrm{~g} \mathrm{~cm}^{-3}$

\section{Quantum chemical calculation}

The ab initio characterization of MDMB-4en-PINACA was performed on DFT [23] B3LYP level in gas phase, where only $R$-enantiomer was considered. Conformational analysis was performed to obtain stable compound geometries. During the rotamers searching process, the molecular mechanics with MMFF94 force field revealed 73 conformers that were subsequently used for further ab initio computation. Initial geometry optimization was performed with the B3LYP functional and 6-31G basis set. To avoid high computational costs, the frequency calculation was not performed. The obtained results indicated the presence of 5 stable lowestenergy conformers. To prove that the minima of energy were reached, the obtained stable geometries were re-optimized and subjected to vibrational analysis using the B3LYP functional and 6-311++G(d,p) basis set. The structures of the re-optimized conformers and their relative populations are presented in Fig. S9. As results from the figure, the final conformers contained amide protons with hydrogen bonds towards the closest hydrogen acceptors: indazole $2 \mathrm{H}$ nitrogen and carbonyl oxygen. The $\mathrm{H}$ bond length of 2.3 and $2.5 \AA$ for $\mathrm{N}-\mathrm{H}$ and $\mathrm{H}-\mathrm{O}$ pairs, respectively, indicated strong character of these interactions. Intramolecular hydrogen bonding seemed to be the interaction stabilizing the lowestenergy conformers. Moreover, the rigid position of the ester group, forced by intramolecular bonding, did not allow for conformational flexibility of methyl and tert-butyl fragments. These groups were similarly oriented in all the stable conformers. The alkyl chain was the only MDMB-4enPINACA fragment with position differing between the obtained rotamers. The conformers $d$ and e are the most stable energetically (conformer e had only slightly higher 


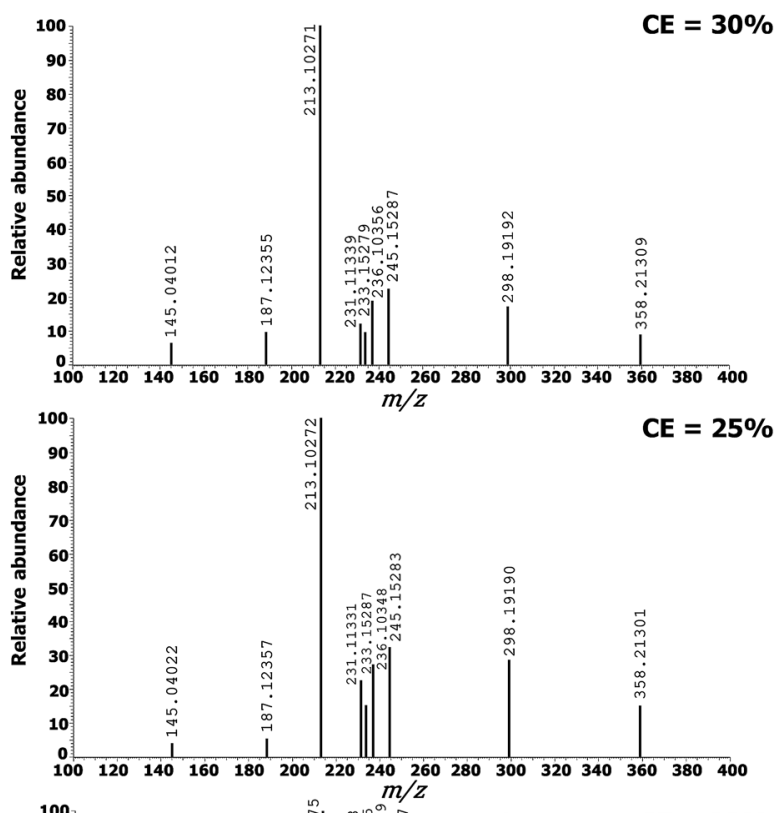

energy), which leads to their similar abundances-38 and $36 \%$, respectively. The other conformations of pent-4-enyl chain only slightly increased the energy of the moleculethe differences in free energy between all of the conformers did not exceed $2 \mathrm{kcal} / \mathrm{mol}$.

\section{IR spectroscopy}

The IR spectrum of the examined material is presented in Fig. S10. Its interpretation was as follows:

- Sharp band at $3412 \mathrm{~cm}^{-1}$ represented $\mathrm{N}-\mathrm{H}$ stretching of amide group;

- Alkyl C-H stretching vibrations gave rise to the signal in the $3000-2800 \mathrm{~cm}^{-1}$ region;

- Weak aromatic and alkene $\mathrm{C}-\mathrm{H}$ stretching bands were present in the region from 3100 to $3000 \mathrm{~cm}^{-1}$

- Ester and amide carbonyl group modes appeared at 1727 and $1666 \mathrm{~cm}^{-1}$, respectively.

To conduct the assignment of the most important absorption bands below $1600 \mathrm{~cm}^{-1}$, the analysis of theoretically obtained harmonic frequencies was performed, using conformer $\mathrm{d}$ with highest abundance. The theoretical harmonic frequencies of normal modes computed on the B3LYP/6-311++G(d,p) level of theory were scaled using the least square methods on the basis of experimental wavenumbers of the most prevalent absorption bands below $1600 \mathrm{~cm}^{-1}$. The obtained scaling factor was 0.980 . The scaled frequencies and calculated intensities of rotamer $\mathrm{d}$ were subsequently used for the assignment of normal modes of the experimental signals. Table 3 presents the assigned bands. Several bands of the considered spectral range were assigned to the normal modes of indazole and vinyl groups. The region of $1600-1300 \mathrm{~cm}^{-1}$ contains multiple singals from the stretching of indazole ring with aromatic $\mathrm{C}-\mathrm{H}$ rocking. The out-of-plane modes of indazole were assigned to the signals from the range of $1000-700 \mathrm{~cm}^{-1}$. For the vinyl moiety, 1007 and $925 \mathrm{~cm}^{-1}$ were correlated with the out-ofplane bending modes of alkene $\mathrm{C}-\mathrm{H}$ bonds. Moreover, the contribution of in-plane bending of vinyl was observed for the modes assigned to the positions of 1214 and $1328 \mathrm{~cm}^{-1}$.

\section{Discussion}

The social problems related to the uncontrolled use of psychoactive compounds, including new synthetic cannabinoids, motivate researchers to learn about their properties and to develop methods for their identification. MDMB-4enPINACA is an example of an illegally traded synthetic cannabinoid that requires precise detection procedures. Some fractions of analytical data concerning this compound can

Fig. 4 Product ion mass spectra of MDMB-4en-PINACA as a function collision energy (CE) obtained by high-resolution-tandem mass spectrometry 


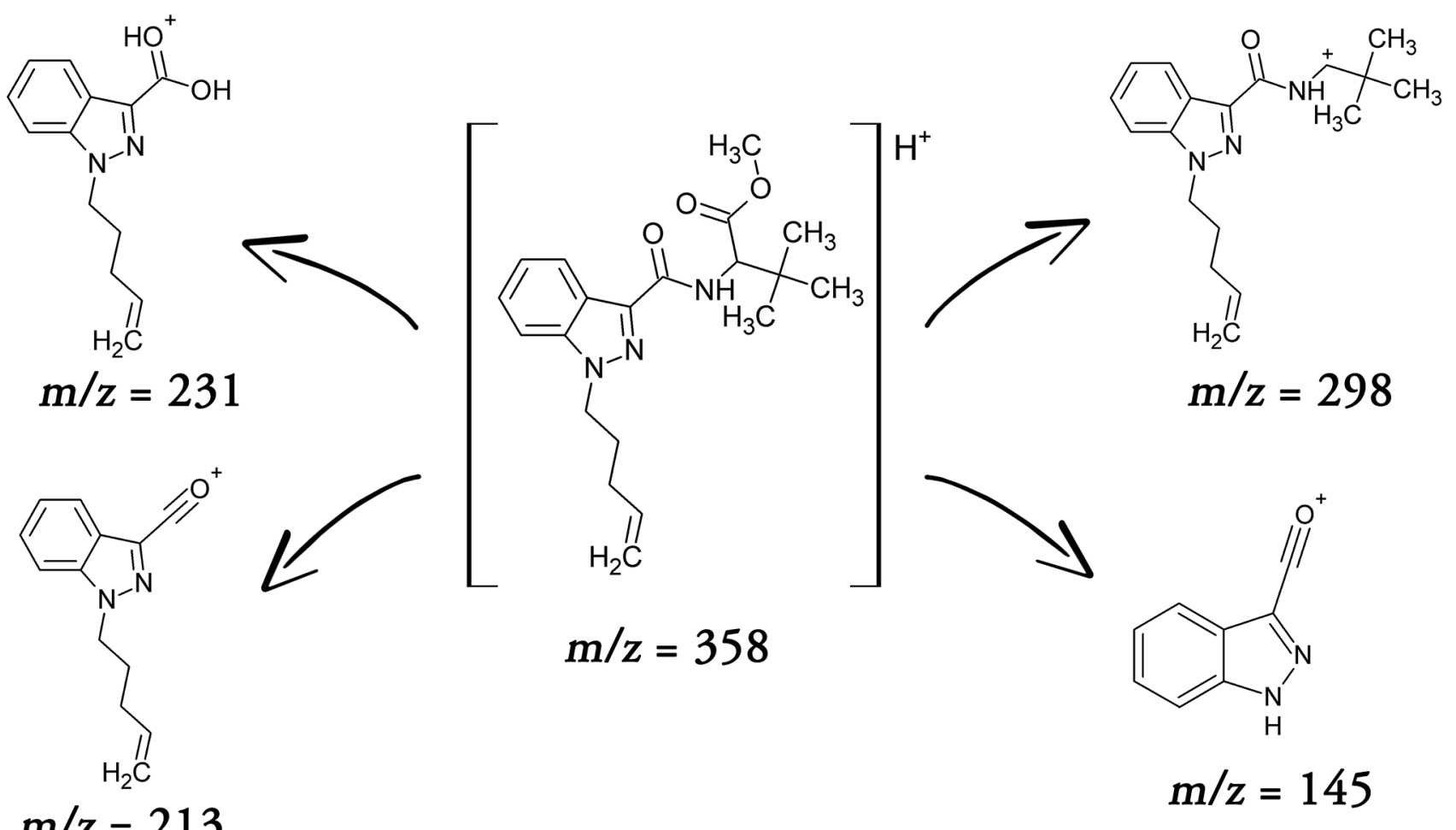

Fig. 5 Fragmentation pathways of MDMB-4en-PINACA by electrospray ionization mass spectrometry

Table 2 Nuclear magnetic resonance spectroscopic data of MDMB-4en-PINACA in $\mathrm{CDCl}_{3}$

\begin{tabular}{|c|c|c|c|c|c|}
\hline No & ${ }^{1} \mathrm{H}$ & ${ }^{13} \mathrm{C}$ & COSY & HMBC & NOESY \\
\hline 3 & - & 136.7 & - & - & - \\
\hline $3^{\prime}$ & - & 122.9 & - & - & - \\
\hline 4 & $8.35(\mathrm{brd}, J=8.2 \mathrm{~Hz}, 1 \mathrm{H})$ & 122.8 & H5; H6 or H7 & $\mathrm{C} 3, \mathrm{C} 6, \mathrm{C} 7{ }^{\prime}, \mathrm{C} 7$ & H5 \\
\hline 5 & $7.26(\mathrm{ddd}, J=8.2,5.7,2.1 \mathrm{~Hz}, 1 \mathrm{H})$ & 122.6 & Overlapped $\mathrm{H} 6$ and $\mathrm{H} 7$ & $\mathrm{C} 3^{\prime}, \mathrm{C} 7$ & H6 \\
\hline 6 & $7.38-7.42(\mathrm{~m}, 1 \mathrm{H})$ & 126.7 & - & C7 & - \\
\hline 7 & $7.38-7.42(\mathrm{~m}, 1 \mathrm{H})$ & 109.2 & - & $\mathrm{C} 7$ & $\mathrm{H} 1 \mathrm{a}, \mathrm{H} 2 \mathrm{a}, \mathrm{H} 3 \mathrm{a}$ \\
\hline $7^{\prime}$ & - & 140.9 & - & - & - \\
\hline $1 \mathrm{a}$ & $4.41(\mathrm{t}, J=6.9 \mathrm{~Hz}, 2 \mathrm{H})$ & 48.6 & $\mathrm{H} 2 \mathrm{a}$ & $\mathrm{C} 2 \mathrm{a}, \mathrm{C} 3 \mathrm{a}, \mathrm{C} 7$ & $\mathrm{H} 2 \mathrm{a}, \mathrm{H} 3 \mathrm{a}$ \\
\hline $2 \mathrm{a}$ & $2.04-2.09(\mathrm{~m}, 2 \mathrm{H})$ & 28.7 & - & $\mathrm{C} 1 \mathrm{a}, \mathrm{C} 3 \mathrm{a}, \mathrm{C} 4 \mathrm{a}$ & - \\
\hline $3 \mathrm{a}$ & $2.09-2.13(\mathrm{~m}, 2 \mathrm{H})$ & 30.7 & H4a, H5a, H5a' & $\mathrm{C} 1 \mathrm{a}, \mathrm{C} 2 \mathrm{a}, \mathrm{C} 4 \mathrm{a}, \mathrm{C} 5 \mathrm{a}$ & H4a, H5a \\
\hline $4 \mathrm{a}$ & $5.82(\mathrm{ddt}, J=16.9,10.5,6.4 \mathrm{~Hz}, 1 \mathrm{H})$ & 137.0 & $\mathrm{H} 5 \mathrm{a}^{\prime}, \mathrm{H} 5 \mathrm{a}$ & $\mathrm{C} 2 \mathrm{a}, \mathrm{C} 3 \mathrm{a}$ & - \\
\hline $5 \mathrm{a}$ & $5.06(\mathrm{dd}, J=16.8,1.6 \mathrm{~Hz}, 1 \mathrm{H})$ & 115.9 & - & $\mathrm{C} 3 \mathrm{a}, \mathrm{C} 4 \mathrm{a}$ & - \\
\hline $5 a^{\prime}$ & $5.04(\mathrm{dd}, J=10.2,1.4 \mathrm{~Hz}, 1 \mathrm{H})$ & & - & $\mathrm{C} 3 \mathrm{a}$ & - \\
\hline $1 b$ & - & 162.3 & - & - & - \\
\hline $2 b$ & $7.56(\mathrm{~d}, J=9.8 \mathrm{~Hz}, 1 \mathrm{H})$ & - & $\mathrm{H} 3 \mathrm{~b}$ & $\mathrm{C} 1 \mathrm{~b}$ & $\mathrm{H} 3 \mathrm{~b}, \mathrm{H} 5 \mathrm{~b}$ \\
\hline $3 b$ & $4.74(\mathrm{~d}, J=9.7 \mathrm{~Hz}, 1 \mathrm{H})$ & 59.5 & - & $\mathrm{C} 1 \mathrm{~b}, \mathrm{C} 4 \mathrm{~b}, \mathrm{C} 5 \mathrm{~b}, \mathrm{C} 6 \mathrm{~b}$ & $\mathrm{H} 5 \mathrm{~b}$ \\
\hline $4 \mathrm{~b}$ & - & 35.0 & - & - & - \\
\hline $5 b$ & $1.10(\mathrm{~s}, 9 \mathrm{H})$ & 26.7 & - & $\mathrm{C} 3 \mathrm{~b}, \mathrm{C} 4 \mathrm{~b}$ & - \\
\hline $6 b$ & - & 172.2 & - & - & - \\
\hline $7 b$ & $3.76(\mathrm{~s}, 3 \mathrm{H})$ & 51.8 & - & $\mathrm{C} 6 \mathrm{~b}$ & - \\
\hline
\end{tabular}

For carbon skeleton numbers of MDMB-4en-PINACA, see Fig. 1

$\operatorname{COSY}{ }^{1} \mathrm{H}-{ }^{1} \mathrm{H}$ correlation spectroscopy, $\operatorname{HMBC}{ }^{1} \mathrm{H}-{ }^{13} \mathrm{C}$ heteronuclear multiple bond correlation spectroscopy, NOESY ${ }^{1} \mathrm{H}-{ }^{1} \mathrm{H}$ nuclear Ovenhausen effect spectroscopy 
Table 3 Theoretical assignments of the most important absorption bands of infrared spectrum of MDMB-4en-PINACA in the region below $1600 \mathrm{~cm}^{-1}$

\begin{tabular}{|c|c|c|c|c|c|}
\hline $\begin{array}{l}\text { Experimental } \\
\text { frequency }\left[\mathrm{cm}^{-1}\right]\end{array}$ & $\begin{array}{l}\text { Theoretical fre- } \\
\text { quency }\left[\mathrm{cm}^{-1}\right]\end{array}$ & $\begin{array}{l}\text { Scaled theoretical } \\
\text { frequency }\left[\mathrm{cm}^{-1}\right]\end{array}$ & Description of normal modes ${ }^{\mathrm{a}}$ & $\begin{array}{l}\text { Calculated inten- } \\
\text { sity }[\mathrm{km} / \mathrm{mol}]\end{array}$ & $\begin{array}{l}\text { Experi- } \\
\text { mental } \\
\text { intensity }\end{array}$ \\
\hline 1575 & 1608 & 1575 & Indazole $\mathrm{C}-\mathrm{C}, \mathrm{C}-\mathrm{N}$ and $\mathrm{N}-\mathrm{N}$ stretch; in-plane bend of indazole $\mathrm{C}-\mathrm{H}$ & 8.5 & vw \\
\hline 1519 & 1551 & 1519 & $\begin{array}{l}\text { In-plane bend of amide } \mathrm{N}-\mathrm{H} \text { and methine } \mathrm{C}-\mathrm{H} \text {; indazole } \mathrm{C}-\mathrm{C} \text { stretch } \\
\text { with } \mathrm{C}-\mathrm{H} \text { in-plane bend }\end{array}$ & 495.3 & vs \\
\hline 1490 & 1521 & 1490 & $\begin{array}{l}\text { Asymmetric in-plane bend of tert-butyl C-H; in-plane bend of amide } \\
\mathrm{N}-\mathrm{H} \text {; indazole } \mathrm{C}-\mathrm{C} \text { and } \mathrm{C}-\mathrm{N} \text { stretch with } \mathrm{C}-\mathrm{H} \text { in-plane bend }\end{array}$ & 65.8 & $\mathrm{~s}$ \\
\hline 1474 & 1502 & 1471 & $\begin{array}{l}\text { Symmetric in-plane bend of methylene } \mathrm{C}-\mathrm{H} \text {; indazole } \mathrm{C}-\mathrm{C} \text { and } \mathrm{C}-\mathrm{N} \\
\text { stretch with } \mathrm{C}-\mathrm{H} \text { in-plane bend }\end{array}$ & 18.6 & $\mathrm{~m}$ \\
\hline 1438 & 1469 & 1439 & Symmetric in-plane $\mathrm{C}-\mathrm{H}$ bend of ester methyl; ester $\mathrm{C}-\mathrm{C}-\mathrm{O}$ stretch & 17.8 & $\mathrm{~m}$ \\
\hline 1405 & 1437 & 1407 & $\begin{array}{l}\text { Symmetric in-plane bend of tert-butyl C-H; in-plane bend of } \\
\text { methine } \mathrm{C}-\mathrm{H} \text {; indazole } \mathrm{C}-\mathrm{C} \text { and } \mathrm{C}-\mathrm{N} \text { stretch with } \mathrm{C}-\mathrm{H} \text { in-plane } \\
\text { bend }\end{array}$ & 7.0 & $\mathrm{w}$ \\
\hline 1367 & 1387 & 1359 & $\begin{array}{l}\text { Indazole } \mathrm{C}-\mathrm{C}, \mathrm{C}-\mathrm{N} \text { and } \mathrm{N}-\mathrm{N} \text { stretch with } \mathrm{C}-\mathrm{H} \text { in-plane bend; in- } \\
\text { plane bend of methine } \mathrm{C}-\mathrm{H}\end{array}$ & 7.2 & $\mathrm{~m}$ \\
\hline 1328 & 1359 & 1331 & $\begin{array}{l}\text { Out-of-plane bend of methine } \mathrm{C}-\mathrm{H} \text { and in-plane bend of amide } \mathrm{N}-\mathrm{H} \text {; } \\
\text { indazole } \mathrm{C}-\mathrm{C} \text { stretch with } \mathrm{C}-\mathrm{H} \text { in-plane bend; ester } \mathrm{C}-\mathrm{C}-\mathrm{O} \text { stretch }\end{array}$ & 205.8 & $\mathrm{~s}$ \\
\hline 1312 & 1343 & 1316 & $\begin{array}{l}\text { Out-of-plane bend of methylene } \mathrm{C}-\mathrm{H} \text {; indazole } \mathrm{N}-\mathrm{N} \text { and } \mathrm{C}-\mathrm{C} \text { stretch } \\
\text { with } \mathrm{C}-\mathrm{H} \text { in-plane bend }\end{array}$ & 55.3 & $\mathrm{~s}$ \\
\hline 1264 & 1309 & 1282 & $\begin{array}{l}\text { Out-of-plane bend of methylene } \mathrm{C}-\mathrm{H} \text {; indazole } \mathrm{C}-\mathrm{H} \text { in-plane bend } \\
\text { with } \mathrm{N}-\mathrm{N} \text { and } \mathrm{C}-\mathrm{C} \text { stretch }\end{array}$ & 5.5 & $\mathrm{w}$ \\
\hline 1215 & 1238 & 1213 & $\begin{array}{l}\text { tert-Butyl in-plane bend of } \mathrm{C}-\mathrm{H} \text { and } \mathrm{C}-\mathrm{C} \text { stretch; out-of-plane bend } \\
\text { of methylene } \mathrm{C}-\mathrm{H} \text {; in-plane bend of amide } \mathrm{N}-\mathrm{H}\end{array}$ & 48.5 & $\mathrm{~s}$ \\
\hline 1165 & 1182 & 1158 & $\begin{array}{l}\text { Ester C-C-O stretch; in-plane bend of methyl C-H; indazole C-H } \\
\text { in-plane bend }\end{array}$ & 128.5 & vs \\
\hline 1137 & 1150 & 1126 & $\begin{array}{l}\text { Amide } \mathrm{C}-\mathrm{N}-\mathrm{C} \text { stretch; indazole } \mathrm{C}-\mathrm{H} \text { in-plane bend with } \mathrm{C}-\mathrm{C}, \mathrm{C}-\mathrm{N} \\
\text { and } \mathrm{N}-\mathrm{N} \text { stretch }\end{array}$ & 58.8 & $\mathrm{~m}$ \\
\hline 1030 & 1048 & 1026 & tert-Butyl C-H in-plane bend; indazole $\mathrm{N}-\mathrm{N}$ and $\mathrm{C}-\mathrm{N}$ stretch & 5.5 & $\mathrm{w}$ \\
\hline 1006 & 1038 & 1017 & Out-of-plane bend of vinyl C-H; C-C stretch & 11.3 & $\mathrm{~m}$ \\
\hline 987 & 1006 & 986 & Ester O-C stretch; C-C stretch; in-plane bend of tert-butyl C-H & 22.9 & $\mathrm{~m}$ \\
\hline 925 & 949 & 930 & Vinyl $=\mathrm{CH} 2$ out-of-plane bend & 52.9 & $\mathrm{~m}$ \\
\hline 909 & 935 & 916 & Delocalized vibrations of tert-leucinate moiety & 16.9 & $\mathrm{~s}$ \\
\hline 858 & 865 & 847 & $\begin{array}{l}\text { Out-of-plane bend of indazole C-H; C-C stretch; out-of-plane bend } \\
\text { of methylene } \mathrm{C}-\mathrm{H}\end{array}$ & 0.3 & vw \\
\hline 833 & 843 & 826 & Delocalized vibrations of tert-leucinate and amide groups & 44.8 & $\mathrm{~m}$ \\
\hline 787 & 800 & 783 & $\begin{array}{l}\text { Out-of-plane bend of indazole } \mathrm{C}-\mathrm{C}, \mathrm{C}-\mathrm{N} \text { and } \mathrm{C}-\mathrm{H} \text {; out-of-plane } \\
\text { bend of amide } \mathrm{C}-\mathrm{C}-\mathrm{N}\end{array}$ & 3.9 & $\mathrm{~m}$ \\
\hline 774 & 796 & 780 & Iin-plane bend of indazole $\mathrm{C}-\mathrm{C}, \mathrm{C}-\mathrm{N}$ and $\mathrm{N}-\mathrm{N}$ & 23.0 & $\mathrm{~m}$ \\
\hline 755 & 762 & 746 & $\begin{array}{l}\text { Out-of-plane bend of indazole C-H, C-C and C-N; out-of-plane } \\
\text { bend of amide C-C-N }\end{array}$ & 47.1 & vs \\
\hline 637 & 647 & 633 & Delocalized vibrations of indazole, amide and pentenyl groups & 7.0 & $\mathrm{~m}$ \\
\hline 602 & 615 & 602 & $\begin{array}{l}\text { Iin-plane bend of indazole } \mathrm{C}-\mathrm{C}, \mathrm{C}-\mathrm{N} \text { and } \mathrm{N}-\mathrm{N} \text {; out-of-plane bend of } \\
\text { amide } \mathrm{N}-\mathrm{H}\end{array}$ & 28.3 & $\mathrm{~m}$ \\
\hline 554 & 593 & 581 & Out-of-plane bend of amide $\mathrm{N}-\mathrm{H}$ & 81.2 & $\mathrm{~s}$ \\
\hline 469 & 455 & 446 & Delocalized vibrations & 19.6 & $\mathrm{~m}$ \\
\hline 436 & 448 & 439 & Delocalized vibrations & 2.6 & $\mathrm{~m}$ \\
\hline
\end{tabular}

The term "delocalized" was employed for the description of normal modes consisting of vibrations of all functional groups in whole molecule or its fragments

$v w$ very weak, $w$ weak, $m$ medium, $s$ strong, $v s$ very strong

${ }^{\text {a }}$ The vibrations involved in every mode are listed according to the decreasing contribution in the normal mode

be found in the literature [11-16]. They are consistent with those we obtained using some basic analytical techniques, such as GC-EI-MS, FTIR spectroscopy, LC-MS and ${ }^{1} \mathrm{H}$ NMR spectroscopy. The present paper reports additional information from product ion spectra at different CEs, 2D NMR, UV-VIS spectroscopy and Powder X-ray diffraction measurements that significantly broadens the analytical knowledge of MDMB-4en-PINACA. 


\section{Crystallographic analysis}

The obtained sample of MDMB-4en-PINACA had welldeveloped crystal line. The material was used for the powder X-ray diffraction. Unfortunately, the sample did not contain monocrystals suitable for the single crystal diffraction. Attempts for the recrystallization did not result in the growth of monocrystals, and it was decided to conduct only powder diffraction measurements. For the acquired powder diffractogram (Fig. S8), the parameters of elementary cell were determined, but the determination of crystal lattice structure was not possible. Although the crystallographic data for synthetic cannabinoids are scarce, it can be seen that most of these compounds form crystals of monoclinic system with density in the range of $1.1-1.4 \mathrm{~g} \mathrm{~cm}^{-3}[17,24]$. Analogous structural features were observed for the MDBM-4en-PINACA sample. For the powder diffraction measurements of organic compounds, majority of the peaks appear in the $2 \theta$ range below $50^{\circ}$. In the case of MDMB-4en-PINACA, most of the significant signals were observed within the mentioned region, with the most intense and characteristic peaks placed below $20^{\circ}$.

\section{NMR analysis}

Most of MDMB-4en-PINACA proton signals were clearly assigned to the corresponding nuclei. The differentiation of the overlapping aromatic and pent-4-en-1-yl chain resonances was conducted using heteronuclear 2D techniques. These could be done due to the greater dispersion of ${ }^{13} \mathrm{C}$ signals for mentioned fragments leading to the well-separated correlation peaks. This was especially useful for 7.38-7.42 ppm signals corresponding to proton $\mathrm{H} 6$ and $\mathrm{H} 7$ (Table 2, Fig. 1).

The acquired 2D NOESY spectrum contained multiple cross-peaks (see Table 2) corresponding to the throughspace correlations between protons. In the case of tertleucinate and indazole groups, observed nuclear Overhauser effect (NOE) signals led to the connectivities similar to those from other 2D spectra. The only novel conformational information was obtained from cross-peaks of pent-4-en-1-yl protons. Signals correlating nuclei $\mathrm{H} 1 \mathrm{a}, \mathrm{H} 2 \mathrm{a}$ and $\mathrm{H} 3 \mathrm{a}$ to the aromatic protons of 7.38-7.42 ppm (Table 2) indicated the presence of small intramolecular distances between considered atoms pairs. Although the 7.38-7.42 ppm region contained overlapping signals from protons $\mathrm{H} 6$ and $\mathrm{H} 7$, the NOE typically occurs, when the internuclei distance does not exceed $4.5 \AA$, which excludes the possibility of NOE for pairs of H6-aliphatic proton. Hence, the aromatic-pent4-en-1-yl cross-peaks were assigned to the correlations H7-H1a, H7-H2a and H7-H3a (see Table 2). Considering the possible conformations of MDMB-4en-PINACA aliphatic chain, it could be noticed that protons $\mathrm{H} 2 \mathrm{a}$ and $\mathrm{H} 3 \mathrm{a}$ may have differing positions and distances with respect to nuclei H7 in particular rotamers. The steric hindrance between considered aliphatic protons may lead to the conformations with $\mathrm{H} 2 \mathrm{a}$ being in close proximity to aromatic proton, and H3a with distance to $\mathrm{H} 7$ greater than $4 \AA$, and opposite situation with $\mathrm{H} 3 \mathrm{a}$ oriented near $\mathrm{H} 7$ nucleus. The former conformation would lead to the NOE cross-peak occurring only between $\mathrm{H} 7$ and $\mathrm{H} 2 \mathrm{a}$, while the latter would give correlation signal for pair H7-H3a. As those correlations were observed in 2D NOESY, it indicates that MDMB-4en-PINACA rotamers occurring in solution contain both of the described $\mathrm{H} 2 \mathrm{a}$ and H3a orientations. Moreover, very weak cross-peaks between vinyl and aromatic protons were also observed indicating long intramolecular distances between nuclei or small abundance of rotamers with these structural feature.

\section{Conformational analysis of MDMB-4en-PINACA}

Although multitude of physicochemical techniques can be employed for structural characterization of synthetic cannabinoids, only the single crystal X-ray diffraction is able to determine precisely the atom positions and the resulting conformations. The other way is to perform the geometry optimization of the molecule by quantum chemical methods. The results obtained using B3LYP DFT [23] functional for MDMB-4en-PINACA indicate the presence of five stable conformers of the molecule (see Fig. S9 in supplementary material). For each of the obtained rotamers, the conformation of carboxamide moiety is fixed by intramolecular hydrogen bonding. The amide group, which is one of the synthetic cannabinoid parts responsible for the bonding to the cannabinoidical receptors, should have a substituent generating steric hindrance required for effective binding [25]. The position of the tert-leucinate group, a steric substituent in MDMB-4en-PINACA, does not change during conformational transitions. The only fragment of MDMB-4en-PINACA with conformational flexibility is the pentenyl chain. Considering the structures of the obtained rotamers and their populations, none of the determined chain orientations is highly favored over others (see abundances of rotamers at Fig. S9 caption). Although the presence of the alkene double bond may suggest the possibility of $\pi-\pi$ stacking with the indazole ring, such interaction did not occur in the stable conformers. This fact is also confirmed by the experimental results. In the case of $\pi-\pi$ stacking, the centers of interacting groups are in close proximity, which leads to multiple NOE signals between the protons of the interacting groups. 2D NOESY spectrum showed only a very small correlation signal of protons $5 \mathrm{a}$ and 7 (see Table 2, Fig. 1), which is consistent with the edge-to-edge orientation of the vinyl and indazole ring in conformers a and b (see Fig. S9). The lack of $\pi-\pi$ interactions is related to the polarized electrostatic 
nature of the indazole ring. The nitrogen atoms of the indazole and carbonyl group attached to the ring cause a significant polarization of aromatic moiety leading to the change in its quadrupole moment. A significant negative partial charge, being a component of the quadrupole moment, is distributed above both aromatic ring faces in the aromatic rings without electron-withrawing motifs [25]. For the indazole part of MDMB-4en-PINACA, the negative partial charge is distributed in the regions close to the nitrogen atoms. On the other hand, in the subsequent region of the heteroaromatic group, the deficit of electron density is observed. This distribution of electrostatic potential favors $\pi-\pi$ interactions to the $\pi$ fragments with electron realizing groups. No such effect was observed in MDMB-4en-PINACA due to fact that only a simple vinyl group is present in the described analyte.

\section{IR spectroscopy}

GC-MS and ATR-FTIR are most frequently used in routine identification of synthetic cannabinoids, including MDMB-4en-PINACA. In these cases, the substance identification is based on the comparison of EI mass spectra or infrared spectra with those in the database (e.g., NIST database or SWGDRUG mass spectral library). Although it ensures fast routine workflow, a more elaborate analysis of the EI and IR spectra should also be conducted. It is especially apparent for the vibrational spectra of carboxyamideindazole with regions below $1600 \mathrm{~cm}^{-1}$ being the place of multiple signals (Fig. S10). Most of the bands appearing in these range cannot be simply assigned with the "rule of thumb" as little is known about the character of their normal modes, e.g. for MDMB-4en-PINACA. For this compound, it is difficult to differentiate between the bands of indazole and vinyl vibrations and those of alkyl and carbonyl fragments in the range of low wavenumbers. The theoretical vibrational analysis of MDMB-4en-PINACA allowed us to assign the positions of the multiple bands to the stretching and the out-of-plane bending modes of the indazole ring in the regions of $1600-1300 \mathrm{~cm}^{-1}$ and of $1000-700 \mathrm{~cm}^{-1}$, respectively. Yet, the indazole normal modes are influenced by the vibrations of the rest of the molecule. The normal modes of the ring stretching $\left(1600-1300 \mathrm{~cm}^{-1}\right)$ involve the aromatic $\mathrm{C}-\mathrm{H}$ bond rocking. Moreover, a small contribution of $\mathrm{C}-(\mathrm{C}=\mathrm{O})-\mathrm{N}$ bending is observed in the out-of-plane bending modes $\left(1000-700 \mathrm{~cm}^{-1}\right)$. For the vinyl group, the out-of-plane vibrations were assigned to the signals in $1007 \mathrm{~cm}^{-1}$ and $925 \mathrm{~cm}^{-1}$ positions. Contrary to the enlisted modes of indazole, the normal modes of the vinyl group include insignificant contributions from other parts of the molecule.

\section{Conclusions}

MDMB-4en-PINACA, the methyl 3,3-dimethyl-2-(1-(pent4-en-1-yl)- $1 H$-indazole-3-carboxamido)butanoate, is a novel synthetic cannabinoid being the analogue of 5F-ADB with pent-4-en-1-yl fragment in place of 5F-ADB 5-fluoropentyl chain. The present paper is the first comprehensive analytical and structural characterization of MDMB-4en-PINACA obtained by 1D and 2D NMR, GC-MS, LC-PDA-MS, ATRFTIR spectroscopy and powder X-ray diffraction. To derive molecular geometry of MDMB-4en-PINACA and to assign individual band of its FTIR spectrum to individual fragments of the molecule, the quantum calculations with the employment of B3LYP functional were additionally used.

Supplementary Information The online version contains supplementary material available at https://doi.org/10.1007/s11419-021-00573-y.

Acknowledgements We gratefully acknowledge the permission of the Ecotech-Complex in Lublin to use their facilities for the research Project No. UDA-POIG.02.01.00-06-212/09-03.

\section{Declarations}

Conflict of interest There are no financial or other relations that could lead to a conflict of interest.

Ethical approval This article does not contain any studies with human participants or animals performed by any of the authors.

Open Access This article is licensed under a Creative Commons Attribution 4.0 International License, which permits use, sharing, adaptation, distribution and reproduction in any medium or format, as long as you give appropriate credit to the original author(s) and the source, provide a link to the Creative Commons licence, and indicate if changes were made. The images or other third party material in this article are included in the article's Creative Commons licence, unless indicated otherwise in a credit line to the material. If material is not included in the article's Creative Commons licence and your intended use is not permitted by statutory regulation or exceeds the permitted use, you will need to obtain permission directly from the copyright holder. To view a copy of this licence, visit http://creativecommons.org/licenses/by/4.0/.

\section{References}

1. UNODC (2020) World drug report 2020, booklet 4: cross-cutting issues: evolving trends and new challenges. https://wdr.unodc.org/ wdr2020/field/WDR20_BOOKLET_4.pdf. Accessed 10 Dec 2020

2. Kaneko S (2017) Motor vehicle collisions caused by the "superstrength" synthetic cannabinoids, MAM-2201, 5F-PB-22, 5F-ABPINACA, 5F-AMB and 5F-ADB in Japan experienced from 2012 to 2014. Forensic Toxicol 35:244-251. https://doi.org/10.1007/ s11419-017-0369-6 (open access article)

3. Tait RJ, Caldicott D, Mountain D, Hill SL, Lenton S (2016) A systematic review of adverse events arising from the use of synthetic cannabinoids and their associated treatment. Clin Toxicol 54:1-13. https://doi.org/10.3109/15563650.2015.1110590 
4. Schoeder CT, Hess C, Madea B, Meiler J, Müller CE (2018) Pharmacological evaluation of new constituents of "Spice": synthetic cannabinoids based on indole, indazole, benzimidazole and carbazole scaffolds. Forensic Toxicol 36:385-403. https://doi.org/10. 1007/s11419-018-0415-z (open access article)

5. Buchler IP, Hayes MJ, Hedge SG, Hockerman SL, Jones DE, Kortum SW, Rico JG, Tenbrick RE, Wu KK (2009) Indazole derivatives. WO 2009/106982/A1

6. Buchler IP, Hayes MJ, Hedge SG, Hockerman SL, Jones DE, Kortum SW, Rico JG, Tenbrick RE, Wu KK (2009) Indazole derivatives. WO 2009/106980/A2

7. Grafinger KE, Mandhair HK, Broillet A, Gertsch J, Weinmann W (2019) Cytotoxicity of the synthetic cannabinoids 5C-AKB48, 5F-MDMB-PINACA, ADB-CHMINACA, MDMB-CHMICA and NM-2201 in A549 and TR146 cell lines. Forensic Toxicol 37:398-411. https://doi.org/10.1007/s11419-019-00474-1

8. EMCDDA (2018) Report on the risk assessment of $N$-(1-amino3-methyl-1-oxobutan-2-yl)-1-(cyclohexylmethyl)- $1 H$-indazole3 -carboxamide (AB-CHMINACA) in the framework of the Council Decision on new psychoactive substances. EMCDDA, Luxemburg. https://doi.org/10.2810/565855

9. Wiley JL, Marusich JA, Huffman JW (2014) Moving around the molecule: relationship between chemical structure and in vivo activity of synthetic cannabinoids. Life Sci 97:55-63. https://doi. org/10.1016/j.lfs.2013.09.011

10. Langer N, Lindigkeit R, Schiebel H-M, Papke U, Ernst L, Beuerle $\mathrm{T}$ (2016) Identification and quantification of synthetic cannabinoids in "spice-like" herbal mixtures: update of the German situation for the spring of 2016. Forensic Sci Int 269:31-41. https:// doi.org/10.1016/j.forsciint.2016.10.023

11. Krotulski AJ, Cannaert A, Stove C, Logan BK (2021) The next generation of synthetic cannabinoids: detection, activity, and potential toxicity of pent-4en and but-3en analogues including MDMB-4en-PINACA. Drug Test Anal. https://doi.org/10.1002/ dta. 2935

12. Watanabe S, Vikingsson S, Åstrand A, Gréen H, Kronstrand R (2020) Biotransformation of the new synthetic cannabinoid with an alkene, MDMB-4en-PINACA, by human hepatocytes, human liver microsomes, and human urine and blood. AAPS J 22:13. https://doi.org/10.1208/s12248-019-0381-3

13. Ozturk YE, Yeter O (2020) In vitro phase I metabolism of the recently emerged synthetic MDMB-4en-PINACA and its detection in human urine samples. J Anal Toxicol 44:976-984. https:// doi.org/10.1093/jat/bkaa017

14. National Forensic Laboratory, Slovenia (2018) Analytical report: MDMB-PINACA N1-pentyl-4-en isomer (MDMB-4en-PINACA). https://www.policija.si/apps/nfl_response_web/0_Analy tical_Reports_final/MDMB-4en-PINACA\%20(MDMB-PINACA\%20N1-pentyl-4-en\%20isomer)-ID-1951-18\%20_report. pdf. Accessed 15 Jul 2020

15. Norman C, Walker G, McKirdy B, McDonald C, Fletcher D, Antonides LH, Sutcliffe OB, Nic Daéid N, McKenzie C (2020)
Detection and quantitation of synthetic cannabinoid receptor agonists in infused papers from prisons in a constantly evolving illicit market. Drug Test Anal 12:538-554. https://doi.org/10.1002/dta. 2767

16. WHO (2020) Critical review report: MDMB-4en-PINACA. Expert Committee on Drug Dependence, forty-third meeting, Geneva, 12-20 October 2020. https://www.who.int/docs/defau lt-source/controlled-substances/43rd-ecdd/mdmb-4en-pinacareview-2020.pdf?sfvrsn=5cd6e97e_4. Accessed 20 Feb 2021

17. Dybowski MP, Holowinski P, Typek R, Dawidowicz AL (2021) Comprehensive analytical characteristics of $N$-(adamantan-1-yl)1-(cyclohexylmethyl)- $1 \mathrm{H}$-indazole-3-carboxamide (ACHMINACA). Forensic Toxicol 39:230-239. https://doi.org/10.1007/ s11419-020-00547-6 (open access article)

18. Gonzalez FR, Nardillo AM (1999) Retention index in temperature-programmed gas chromatography. J Chromatogr A 842:2949. https://doi.org/10.1016/S0021-9673(99)00158-2

19. Halgren TA (1996) Merck molecular force field. I. Basis, form, scope, parameterization, and performance of MMFF94. J Comput Chem 17:490-519. https://doi.org/10.1002/(SICI)1096987X(199604)17:5/6\%3c490::AID-JCC1\%3e3.0.CO;2-P

20. Becke AD (1993) Density-functional thermochemistry. III. The role of exact exchange. J Chem Phys 98:5648. https://doi.org/10. 1063/1.464913

21. Aprà E, Bylaska EJ, de Jong WA, Govind N, Kowalski K, Straatsma TP, Valiev M, van Dam HJJ, Alexeev Y, Anchell J, 104 authors (2020) NWChem: past, present, and future. J Chem Phys 152:184102. https://doi.org/10.1063/5.0004997 (open access article)

22. Worst TJ, Sprague JE (2015) The "pharmacophore rule" and the "spices." Forensic Toxicol 33:170-173. https://doi.org/10.1007/ s11419-014-0243-8

23. Orio M, Pantazis DA, Neese F (2009) Density functional theory. Phytosynth Res 102:443-453. https://doi.org/10.1007/ s11120-009-9404-8

24. Bulska E, Bachliński R, Cyrański MK, Michalska-Kacymirow M, Kośnik W, Małecki P, Grela K, Dobrowolski MA (2020) Comprehensive protocol for the identification and characterization of new psychoactive substances in the service of law enforcement agencies. Front Chem 8:693. https://doi.org/10.3389/fchem.2020. 00693 (open access article)

25. Martinez CR, Iverson BL (2012) Rethinking the term "pi-stacking." Chem Sci 3:2191-2201. https://doi.org/10.1039/C2SC2 $0045 \mathrm{G}$

Publisher's Note Springer Nature remains neutral with regard to jurisdictional claims in published maps and institutional affiliations. 